\title{
The antagonist of the JAK-1/STAT-1 signaling pathway improves the severity of cerulein-stimulated pancreatic injury via inhibition of NF-kB activity
}

\author{
PING CHEN, LIYA HUANG, YONGPING ZHANG, MINMIN QIAO, WEIYAN YAO and YAOZONG YUAN \\ Department of Gastroenterology, Ruijin Hospital, Shanghai Jiaotong University \\ School of Medicine, Shanghai 200025, P.R. China
}

Received December 2, 2010; Accepted January 19, 2011

DOI: $10.3892 / \mathrm{ijmm} .2011 .632$

\begin{abstract}
The Janus kinase/signal transducer and activator of transcription (JAK/STAT) signaling pathway is widely involved in cell migration, apoptosis and inflammation. However, its exact mechanisms in severe acute pancreatitis (SAP) remain unclear. The aim of this study was to explore the activity of the JAK/STAT signaling pathway in pancreatic injury, investigate the functional mechanisms of SAP in vitro, and thus elucidate the underlying therapeutic effects for SAP in vivo. The activation of the JAK-1/STAT-1 signaling pathway and the expessions of TNF- $\alpha$, IL- $1 \beta$ and IL- 6 proteins were investigated in AR42J cells induced with cerulein and treated with either PBS, RPM, or AG490. One group of cells was left untreated as a control group. Subsequently the activity of $\mathrm{NF}-\kappa \mathrm{B}$ was evaluated. Rats were given RPM or AG490 just before the induction of SAP, the severity of which was assessed at $24 \mathrm{~h}$. The findings revealed that the up-regulated expressions of JAK-1/STAT-1, STAT-3 protein were closely correlated with the transcription of TNF- $\alpha$, IL-1 $\beta$, and IL- 6 in cerulein-stimulated cells. Administration of RPM or AG490 decreased the activity of NF- $\kappa B$ and inhibited the release of TNF- $\alpha$, IL- $1 \beta$, and IL-6. The reflective markers of severity of SAP were also decreased by RPM or AG490 treatment compared to SAP rats. This study indicates that the JAK-1/STAT-1 signaling pathway activity is an early event in pancreatic inflammatory injury. Therefore, early treatment with its inhibitors might be beneficial for attenuation of pancreatic injury in SAP.
\end{abstract}

\section{Introduction}

Severe acute pancreatitis (SAP) is an inflammatory disease characterized by interstitial edema, vacuolization, acinar

Correspondence to: Dr Yaozong Yuan, Department of Gastroenterology, Ruijin Hospital, Shanghai Jiaotong University School of Medicine, Shanghai 200025, P.R. China

E-mail: yyz28@medmail.com.cn yuanyz28@yahoo.com.cn

Key words: Janus kinase, signal transducer and activator of transcription, inflammation, nuclear factor- $\mathrm{\kappa B}$, pancreas necrosis, and inflammatory infiltration of the pancreas. Its high mortality makes SAP a real challenge for clinical treatment (1). Although it has become increasingly clear that the excessive inflammatory response is a determining factor in the process of SAP (2), the exact mechanisms that regulate the severity of SAP remain unclear.

The Janus kinase (JAK)/signal transducer and activator of transcription (STAT) signaling pathway is widely involved in cell migration and apoptosis (3). Some studies have shown that the JAK/STAT signaling pathway plays an important role in the inflammatory response. The blockade of the JAK/STAT signaling pathway prevents the lethal effects of the excessive inflammatory response during sepsis $(4,5)$. However, the role of the JAK/STAT signaling pathway in the excessive systemic inflammatory response observed in SAP has not been fully elucidated. In addition, the precise mechanisms determining the effect of the JAK/STAT signaling pathway inhibitors on SAP in relation to the degree of pancreatic injury are largely unclear.

AR42J cells are the currently available cell line that shows receptor expression and signal transduction mechanisms parallel to those of normal pancreatic acinar cells. Therefore, AR42J cells have been widely used as an in vitro model to study the secretion, signal transduction, cytoskeleton function, apoptosis and the pancreatic inflammatory response of the exocrine pancreas (6). Cerulein over-stimulation is known to produce SAP, and it is likely that under these conditions the inflammatory response in the pancreatic acinar cells is increased leading to damage of these cells (7). In the present study, we used AR42J cells to investigate the potential role of the JAK/STAT signaling pathway on the cerulein-induced inflammatory response in an in vitro model of SAP, and further explored its action in rats with SAP.

\section{Materials and methods}

Cells and drugs. AR42J cells (ATCC, Rockville, MD, USA) were cultured in DMEM medium (Gibco-BRL, Gaithersburg, MD, USA) and $10 \%$ fetal bovine serum (Gibco-BRL) in a 1:1 ratio, $100 \mathrm{U} / \mathrm{ml}$ penicillin and $100 \mu \mathrm{g} / \mathrm{ml}$ streptomycin (Sigma, St. Louis, MO, USA) at $37^{\circ} \mathrm{C}$ and $5 \% \mathrm{CO}_{2}$. Cerulein was obtained from Sigma. 
Effects of cerulein on the JAK/STAT signaling pathway in AR42J cells

Cell treatment. AR42J cells were stimulated with cerulein $\left(10^{-8} \mathrm{M}\right)$, or treated with phosphate buffered saline (PBS) to serve as controls. Cells were incubated with tested substances for $24 \mathrm{~h}$ for further study.

JAK/STAT signaling pathway $R T^{2}$ profiler $^{T M}$ PCR array. Total RNA was isolated from cells using TRIzol reagent kits (Invitrogen, Groningen, The Netherlands). cDNA was prepared from $3 \mu \mathrm{g}$ of total RNA with an MMLV reverse transcriptase cDNA synthesis kit (Promega, Madison, WI, USA).

Profiling was performed using the JAK/STAT signaling pathway $\mathrm{RT}^{2}$ profiler PCR array with the QuantiMir system (System Biosciences, Mountain View, CA, USA), a real-time PCR-based array containing a panel of 84 JAK/STAT-related mRNA assays and the U6 transcript for normalization. All operations were performed strictly according to the manufacturer's procedures. The GEArray analyzer software was used for the background subtraction and for data normalization. Genes were considered to be up-regulated if their expression in cerulein-stimulated cells changed at least 2-fold relative to the control.

Western blot analysis. Tissue samples were washed twice with PBS, homogenized with a tissue homogenizer in RIPA buffer (Biyuntian Company, Shanghai, China), and centrifuged at $12,000 \mathrm{x} \mathrm{g}$ at $4^{\circ} \mathrm{C}$ for $10 \mathrm{~min}$. The supernatants were collected and stored at $-80^{\circ} \mathrm{C}$. The protein concentration of each sample was determined by the bicinchoninic acid protein assay (Biyuntian Company). Each sample was adjusted up to the desired protein content of $40 \mu \mathrm{g}$, denatured in loading buffer [62 mM Tris, $10 \%$ glycerol, $2 \%$ sodium dodecyl sulfate (SDS), $0.003 \%$ bromophenol blue] and separated by electrophoresis on a $6 \%$ SDS-polyacrylamide gel at $100 \mathrm{~V}$ for $120 \mathrm{~min}$. The separated proteins were transferred to a polyvinylidene difluoride (PVDF) membrane using transfer

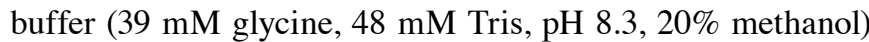
at $200 \mathrm{~mA}$ for $90 \mathrm{~min}$. The membranes were blocked with $5 \%$ non-fat dry milk in Tris-buffered saline (TBS)- $0.1 \%$ Tween for $1 \mathrm{~h}$ at room temperature, washed three times for 10 min each time in TBS- $0.1 \%$ Tween. Membranes were then incubated with one of the following primary antibodies overnight at $4^{\circ} \mathrm{C}$ : JAK-1, phospho-JAK-1 (P-JAK-1), JAK-2, phospho-JAK-2 (P-JAK-2), STAT-1, phospho-STAT-1 (P-STAT1), STAT-3, phospho-STAT-3 (P-STAT-3) (Cell Signaling Biotechnology, Danvers, MA, USA, diluted to 1:1,000), TNF- $\alpha$, IL-1 $\beta$, or IL-6 (Santa Cruz Biotechnology, Inc., Santa Cruz, CA, USA, diluted to 1:500), each in TBS-0.1\% Tween. After being washed 3 times for $10 \mathrm{~min}$ in TBS- $0.1 \%$ Tween, the membranes were incubated with a peroxidase-conjugated IgG secondary antibody (Kangcheng, Shanghai, China) for $1 \mathrm{~h}$ at room temperature. After washing, the proteins were detected by an enhanced chemiluminescence method (Amersham, Piscataway, NJ, USA). The expressions of the proteins were quantified by scanning densitometry using a bio-image analysis system (Bio-Rad, Baltimore, MD, USA). Glyceraldehyde-3-phosphate dehydrogenase (GAPDH) protein levels were determined in a similar manner with an
anti-GAPDH antibody (Sigma; diluted to 1:500) and served as an internal control.

Effects of the JAK/STAT signaling pathway inhibitor on cerulein-stimulated AR42J cells

Cell treatment. The cells were randomly allocated into four groups. Three of the groups were treated with either PBS, rapamycin (RPM, $50 \mathrm{ng} / \mathrm{ml}$, Sigma), or AG490 (50 $\mu \mathrm{mol} / \mathrm{l}$, Sigma) and stimulated with cerulein $\left(10^{-8} \mathrm{M}\right)$ and one group of cells was left untreated as a control. The samples were harvested $24 \mathrm{~h}$ after the onset of stimulation for further study.

Electrophoretic mobility shift assay (EMSA). Nuclear protein extracts of cells were prepared from AR42J cells $24 \mathrm{~h}$ after stimulation with a nuclear protein extraction kit (Pierce Chemical, Rockford, IL, USA). The biotinylated doublestranded DNA probe sequences of NF- $\kappa \mathrm{B}$ (nuclear factor $\kappa \mathrm{B}$ ) were sense 5'-AGTTGAGGGGACTTTCCCAGGC-3' and antisense 3'-TCAACTCCCCTGAAAGGGTCCG-5'.

Nuclear extracts $(5 \mu \mathrm{g})$ were incubated with $5 \mathrm{ng}$ of biotinylated double-stranded DNA probes as above in $20 \mu \mathrm{l}$ of reaction mixture containing binding buffer, $2.5 \%$ glycerol, $0.05 \% \mathrm{NP}-40$, and $50 \mu \mathrm{g} / \mathrm{ml}$ poly dI:dC from the LightShift EMSA kit (Pierce) for $20 \mathrm{~min}$ at room temperature. The mixture was run on $6 \%$ polyacrylamide gel. The DNA was transferred to a PVDF membrane, followed by detection using horseradish peroxidase-conjugated streptavidin and a chemiluminescent substrate from Pierce (Pierce). The EBNA (Epstein-Barr nuclear antigen, provided from Pierce) was used as a control.

Western blot analysis. Cells were treated as described above. The levels of the TNF- $\alpha$, IL- $1 \beta$, IL-6, inhibitor of $\kappa$ B kinase $\beta$

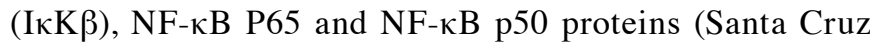
Biotechnology, diluted to 1:500) were assessed by Western blot analysis as described above.

Reverse transcriptase-polymerase chain reaction (RT-PCR). Total RNA was isolated from cells using TRIzol reagent kits (Gibco-BRL). The primers for rat TNF- $\alpha$, IL-1 $\beta$, IL-6 and GAPDH were constructed based on published rat nucleotide sequences and synthesized by Sangon Technology Inc. (Shanghai, China). RT-PCR reactions were performed in $25 \mu \mathrm{l}$ volumes and run in the GeneAmp 9600 instrument (Perkin-Elmer Inc., Wellesley, MA, USA). The sense and antisense primer sequences were as follows: IL-6, sense 5'-TGCCTTCTTGGGACTGAT-3' and antisense 5'-CTGG CTTTGTCTTTCTTGTTAT-3'; IL-1 $\beta$ : sense 5'-TCTGTGA CTCGTGGGATG-3' and antisense 5'-TCTTTGGGTATTGT TTGG-3'; TNF- $\alpha$ : sense 5'-TCTCATTCCTGCTCGTGG-3' and antisense 5'-CCATTGGCCAGGAGGGCGTTGG-3'; GAPDH: sense 5'-GGCTGAGAACGGGAAGCTTGTC-3' and antisense 5'-CAGCCTTCTCCATGGTGGTGAAGA-3'. The RT-PCR conditions were as follows: 1 cycle for $5 \mathrm{~min}$ at $95^{\circ} \mathrm{C} ; 35$ cycles for $45 \mathrm{sec}$ at $94^{\circ} \mathrm{C}$, and for $45 \mathrm{sec}$ at $55^{\circ} \mathrm{C}$ (IL-6, GAPDH) or at $54^{\circ} \mathrm{C}(\mathrm{IL}-1 \beta)$, or at $56^{\circ} \mathrm{C}(\mathrm{TNF}-\alpha)$, and for $1 \mathrm{~min}$ at $72^{\circ} \mathrm{C}$; and 1 cycle for $10 \mathrm{~min}$ at $72^{\circ} \mathrm{C}$. The PCR products were separated by electrophoresis in $1.2 \%$ agarose gels and stained with ethidium bromide. The densities of the cDNA bands were analyzed by scanning densitometry 
using the GelDoc 2000 software (Bio-Rad). The results were expressed as a ratio of the densities relative to the GAPDH band density.

\section{In vivo experiments}

Animals and reagents. Forty male Sprague-Dawley rats weighing 150-200 g were randomly divided into 4 groups: the SAP group $(n=10)$, the RPM- $(n=10)$ or AG490-treated groups $(n=10)$, and the control group $(n=10)$. Twenty-four hours prior to the start of the experiments, the rats were deprived of food but allowed access to water. In rats with SAP, SAP was induced by seven intraperitoneal injections of $50 \mu \mathrm{g} / \mathrm{kg}$ cerulein at $1 \mathrm{~h}$ intervals. In the treated groups, AG490 $(20 \mathrm{mg} / \mathrm{kg})$ or RPM $(0.4 \mathrm{mg} / \mathrm{kg})$ were dissolved in saline and administered by intravenous injection for 1-2 min through the penile vein $30 \mathrm{~min}$ before the induction of SAP. In the control group, the rats only underwent sham operation. An equal volume of saline was administered in the control and SAP rats. All rats were returned to their cages with free-access to water and food after induction. Rats that died before the end of the study (three in the SAP group, two in the RPM-treated group and one in the AG490-treated group) were excluded from the analysis. Blood samples taken from the heart and pancreatic tissues were harvested at $24 \mathrm{~h}$ after the onset of induction before the surviving animals were sacrificed. The experiments were conducted according to the Guidelines of the Shanghai Animal Use and Care Committees and the National Animal Welfare Law.

Histological score of pancreatic injury. Pancreatic tissues were excised and fixed in $4 \%$ formaldehyde. The histopathological evaluation was performed under light microscopy after sectioning and staining with hematoxylin and eosin. The selected slides were forwarded to two pathologists on two separate occasions. The two pathologists, each of whom was blinded to the other's assessment, recorded their assessment on an evaluation form for pancreatic injury. The evaluation of pancreatic injury including the graded assessment of pancreatic edema, vascular, fat necrosis and acinar necrosis. Calcification was determined by the histological score of pancreatic injury (8), which was used to help reach a diagnosis in case of a different opinion between the pathologists.

The methods of histological score of pancreatic injury were as follows: Edema: 0, absent; 1, focal expansion of the interlobar septa; and 2, diffuse expansion of the interlobar septa. Vascular: 0, absent; 1, congestion; 2, congestion plus local interlobar or intralobar hemorrhage; 3, multifocal diffuse hemorrhage; and 4, vascular fibrinoid necrosis or thrombosis. Fat necrosis: 0 , absent; 1 , focal dissolution of the interlobular or peripancreatic fat; and 2, diffuse dissolution of the interlobular or peripancreatic fat. Acinar necrosis: 0, absent; $1,<10 \%$ patchy necrosis of the edges of the lobules; $2,10-30 \%$ patchy, peripheral necrosis of the lobules; $3,<30 \%$ confluent lobules necrosis; $4,<50 \%$ confluent lobular necrosis; and 5, formation of microabscesses. Calcification: 0 , absent; 1 , focal in fat or acinar necrosis; and 2, diffuse in fat or acinar necrosis.

Pancreatic dry/wet weight ratio. Pancreatic tissue edema was evaluated by tissue water content. A portion of the pancreatic tissue was taken immediately after sacrifice, to be trimmed of the fat and weighed. Tissue water content was determined by calculating the wet/dry weight ratio according to the formula: [(wet weight - dry weight)/dry weight] x $100 \%$, where the wet weight was the initial weight of the respective tissue and the weight after incubation at $72^{\circ} \mathrm{C}$ for $24 \mathrm{~h}$ was the dry weight.

Biochemical assays. Serum amylase levels were determined by a Beckman CX7 chemistry analyzer (Beckman Coulter, Fullerton, CA, USA). Serum trypsinogen activation peptide (TAP) levels (Biotrin International Ltd., Dublin, Ireland) were evaluated by an enzyme-linked immunosorbent assay.

Statistical analysis. Data are expressed as the means \pm standard deviations (SD). Statistics were conducted using the Statistical Package for the Social Sciences (SPSS) software, version 10.5. The one-way analysis of variance (ANOVA) with the Dunnett's multiple comparison test were used for comparisons between the means. A P-value $<0.05$ was considered statistically significant.

\section{Results}

JAK/STAT signaling pathway gene expression. The genes that were up-regulated more than 2-fold between the two groups are discussed below. In general, the key genes involved in the inflammatory pathway, such as JAK-1, JAK-2, STAT-1, STAT-3, STAT-4, STAT-5b, the CXC chemokine ligand 9 (CXCL9), the siderophore iron transporter 1 (sit1), the interferon regulatory factor 1 (Irf1), IL-20, Nfkb1 and CRP among others were up-regulated in cerulein-stimulated AR42J cells. On the other hand, negative regulators of JAK/STAT signaling such as the protein inhibitor of activated STAT (PIAS) 1, protein tyrosine phosphates, CD45 (Ptprc), the suppressor of cytokine signaling (SOCS) 1, SOCS2 and SOCS3 were downregulated. These results supported the concept that cerulein could influence the activity of the JAK-1/STAT-1, STAT-3 signaling pathway in AR42J cells.

Expression and activity of JAK-1 STAT-1 and STAT-3 proteins. To gain direct evidence for the activity of the JAK-1/STAT-1, STAT-3 signaling pathway induced by cerulein in AR42J cells, the JAK-1 and STAT-1 and STAT-3 activities were evaluated by Western blot analysis (Fig. 1). Compared with control cells, cerulein increased the levels of JAK-1, P-JAK-1, STAT-1, and P-STAT-1 proteins at $24 \mathrm{~h}(\mathrm{P}<0.05)$. Meanwhile, in ceruleinstimulated cells increased levels of JAK-1 were observed at $12 \mathrm{~h}$ and of P-JAK-1, STAT-1, P-STAT-1, STAT-3, and P-STAT-3 proteins at $24 \mathrm{~h}$, demonstrating a time-dependent response $(\mathrm{P}<0.05$ vs. $6 \mathrm{~h})$.

Expressions of $T N F-\alpha, I L-1 \beta$, and $I L-6$ protein. The Western blot analsysis of the levels of TNF- $\alpha$, IL- $1 \beta$ and IL- 6 protein is presented in Fig. 2. The levels of IL- 6 at $12 \mathrm{~h}$, and IL-1 $\beta$ and TNF- $\alpha$ protein at $6 \mathrm{~h}$ in cerulein-stimulated cells were statistically different from those in control cells $(\mathrm{P}<0.05)$. In addition, the levels of IL- 6 at $12 \mathrm{~h}$, IL-1 $\beta$ at $48 \mathrm{~h}$, and TNF- $\alpha$ protein at $24 \mathrm{~h}$ in cerulein-stimulated cells, were different compared with those of cerulein-stimulated cells at $6 \mathrm{~h}$, respectively, demonstrating that the response was timedependent $(\mathrm{P}<0.05)$. 
A

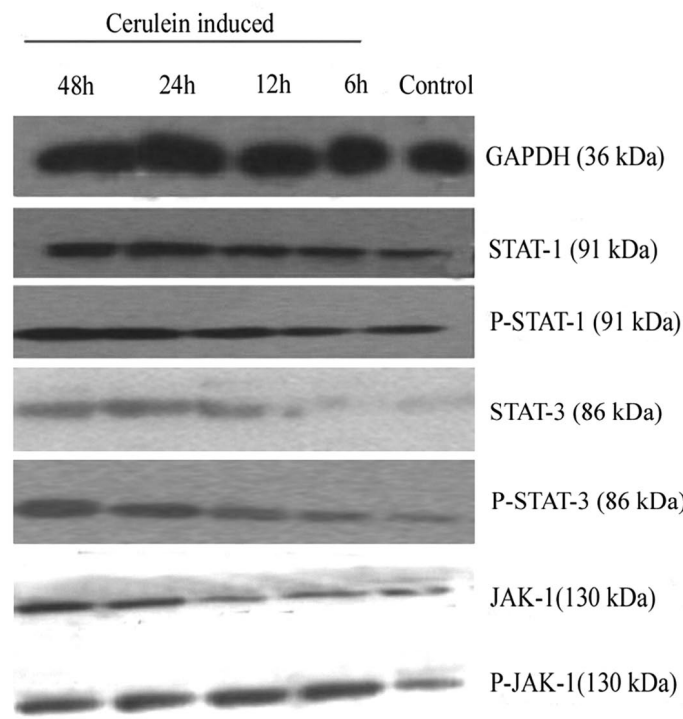

B

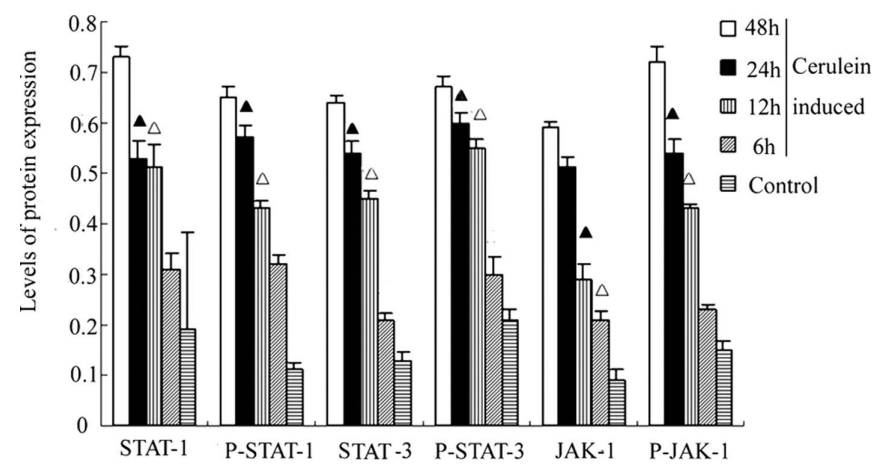

Figure 1. (A) Representative Western blot analysis of proteins in AR42J cells detected with Janus kinase 1 (JAK-1), phospho-JAK-1 (P-JAK-1), signal transducer and activator of transcription 1 (STAT-1), phospho-STAT-1 (P-STAT-1), STAT-3, P-STAT-3 and glyceraldehyde-3-phosphate dehydrogenase (GAPDH) antibodies at different time-points in cerulein-stimulated or control AR42J cells. (B) The graph shows a densitometric analysis of Western blot: the ratio of the JAK-1, P-JAK-1, STAT-1, P-STAT-1, STAT-3, or P-STAT-3 band intensity to that of GAPDH was determined for each group. ${ }^{\wedge} \mathrm{P}<0.05$ vs. control cells; ${ }^{\wedge} \mathrm{P}<0.05$ vs. cerulein-stimulated cells at $6 \mathrm{~h}$.

The effect of RPM or AG490 on the activity of NF- $\kappa B$. EMSA was performed to detect the activity of NF- $\mathrm{KB}$ in each group (Fig. 3). Similarly to the control EBNA system, a complete set of three reactions should be performed with the test system. Very little NF- $\kappa B$ binding activity was detected in control cells and the NF- $\mathrm{KB}$ binding activity was increased in cerulein-stimulated cells at $24 \mathrm{~h}$. Treatment with RPM or AG490 both decreased the NF- $\mathrm{KB}$ binding activity compared to that of cerulein-stimulated cells.

Furthermore, the levels of IKK $\beta$, NF-B p 65 and NF-B P50 protein were investigated (Fig. 4). At $24 \mathrm{~h}$ the levels of IK $\beta$, NF-B P65 and NF-B P50 protein in cerulein-stimulated cells were increased $(\mathrm{P}<0.05$ control cells, respectively), but were down-regulated in RPM- or AG490-treated cells $(\mathrm{P}<0.05$ cerulein-stimulated cells).

Effect of RPM or AG490 on TNF- $\alpha, I L-1 \beta$ and IL-6 protein and gene expression. The effects of RPM or AG490 on the TNF- $\alpha$,
A

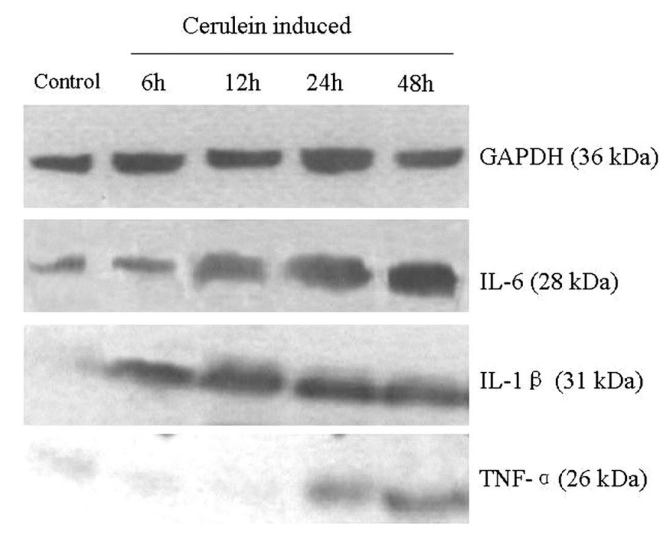

B

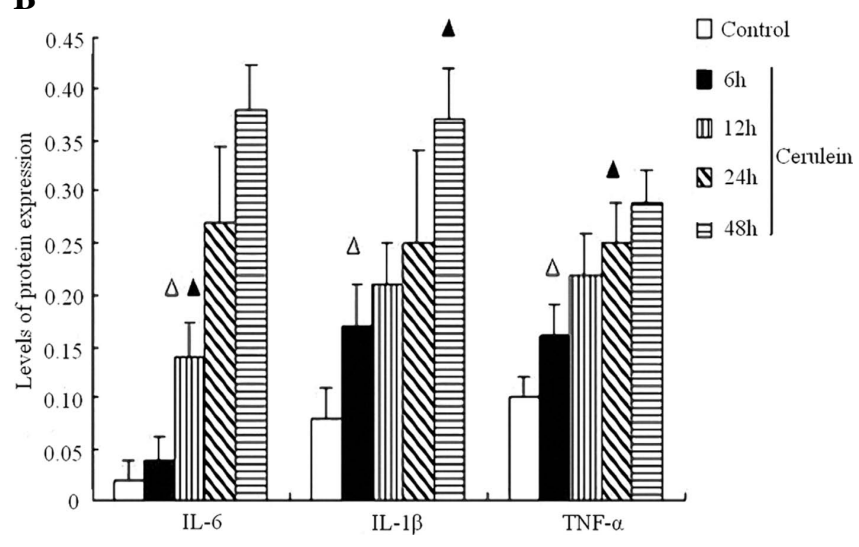

Figure 2. (A) Representative Western blot analysis of proteins in AR42J cells detected with tumor necrosis factor (TNF)- $\alpha$, interleukin (IL)-1 $\beta$, IL-6 and GAPDH antibodies at different time-points in cerulein stimulation or control cells. (B) The graph shows a densitometric analysis of Western blot: the ratio of the TNF- $\alpha$, IL-1 $\beta$, or IL- 6 band density to that of GAPDH was determined for each group. ${ }^{\triangle} \mathrm{P}<0.05$ vs. control cells; ${ }^{\wedge} \mathrm{P}<0.05$ vs. ceruleinstimulated cells at $6 \mathrm{~h}$.

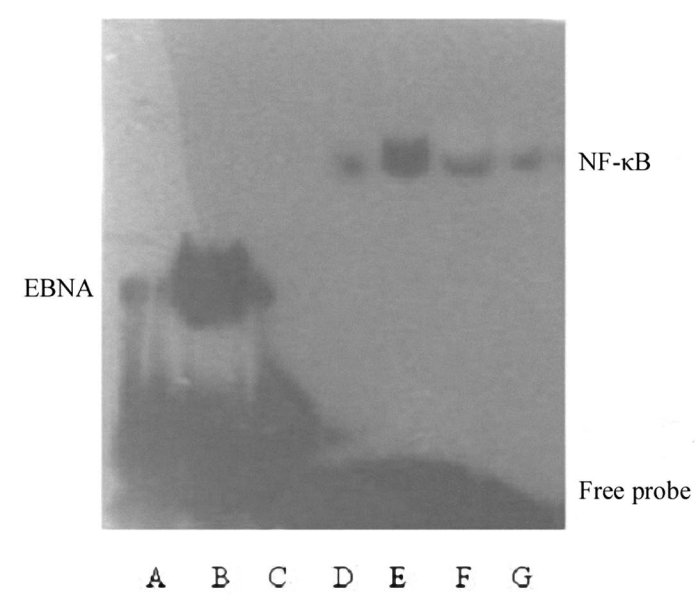

Figure 3. Effect of RPM and AG490 on the activity of NF- $\mathrm{kB}$. Lanes A-C, control EBNA system; A, EBNA; B, EBNA + biotin labeled EBNA probe; C, EBNA + cold EBNA probe; D, control cells; E, cerulein-stimulated cells; F, RPM-treated cells; G, AG490-treated cells.

IL-1 $\beta$, and IL- 6 gene or protein expression were determined by RT-PCR or Western blot analysis (Figs. 5 and 6). The results showed that cerulein caused an increase in the protein levels and gene transcription of TNF- $\alpha$, IL-1 $\beta$, and IL- 6 (P<0.05, control 
A

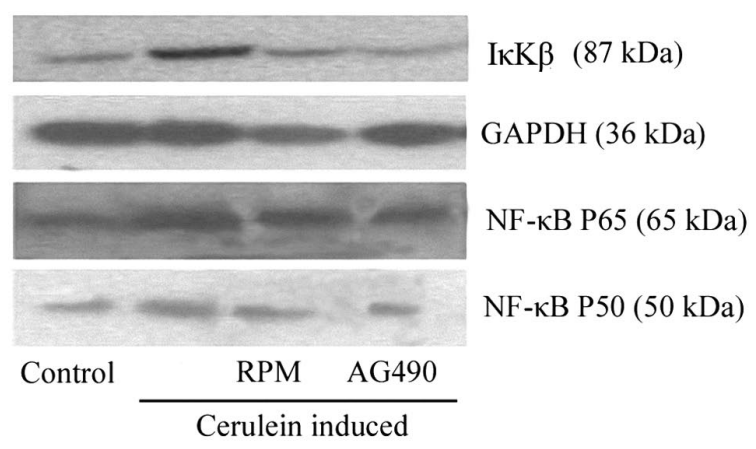

B

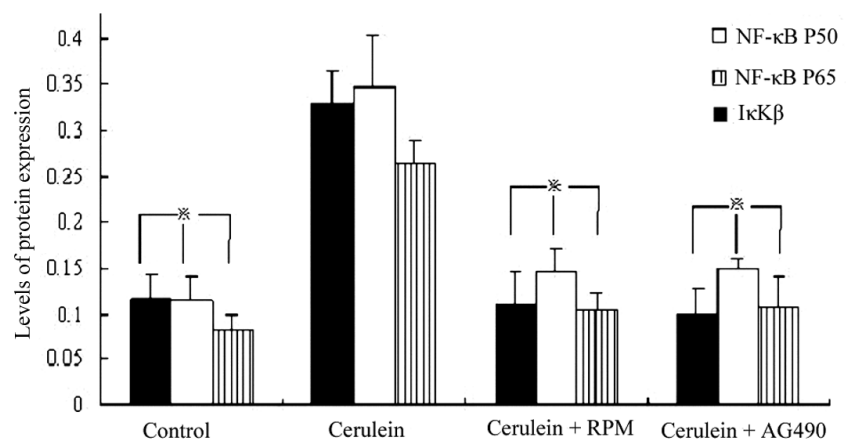

Figure 4. (A) Representative Western blot analysis of proteins in AR42J cells

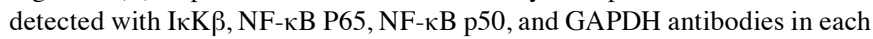
group. (B) The graph shows a densitometric analysis of Western blot: the

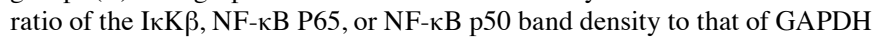
was determined for each group. ${ }^{*} \mathrm{P}<0.05$ vs. cerulein-stimulated cells.

A
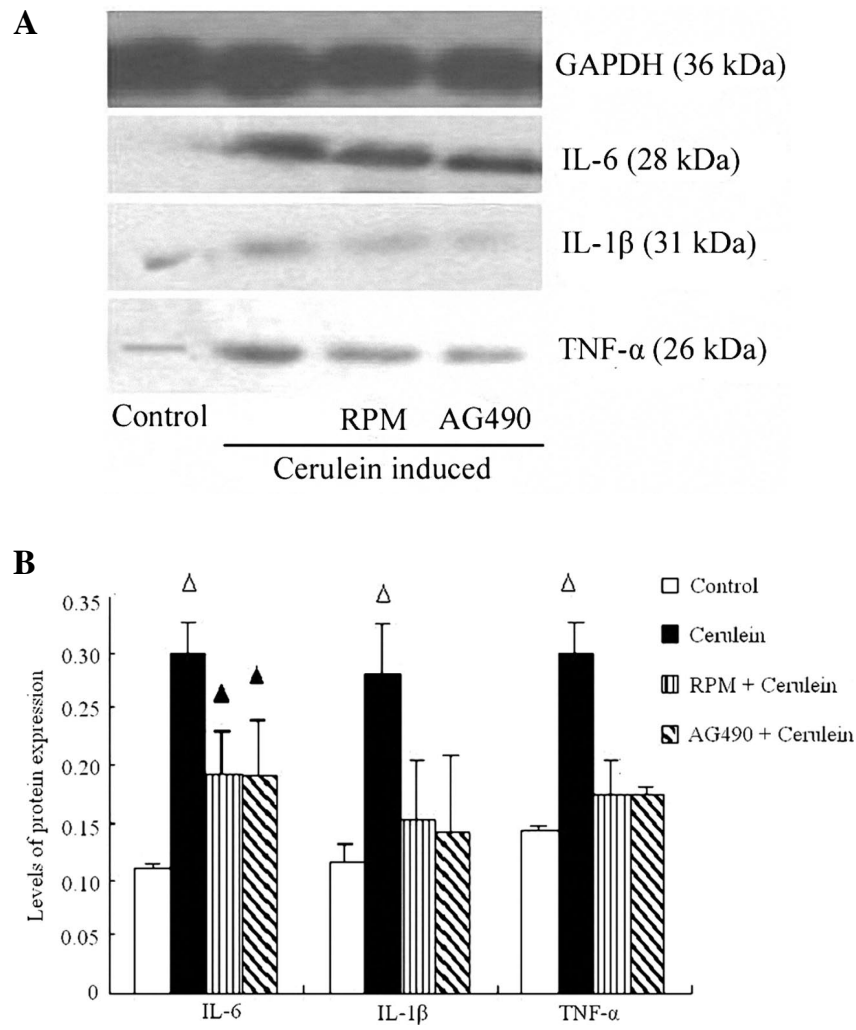

Figure 5. (A) Representative Western blot analysis of proteins in AR42J cells detected with TNF- $\alpha$, IL-1 $\beta$, IL-6, and GAPDH antibodies in each group. (B) The graph shows a densitometric analysis of Western blot: the ratio of the TNF- $\alpha$, IL-1 $\beta$, or IL- 6 band density to that of GAPDH was determined for each group. ${ }^{\triangle} \mathrm{P}<0.05$ vs. cells of all other treatments, ${ }^{\wedge} \mathrm{P}<0.05$ vs. control cells.
A

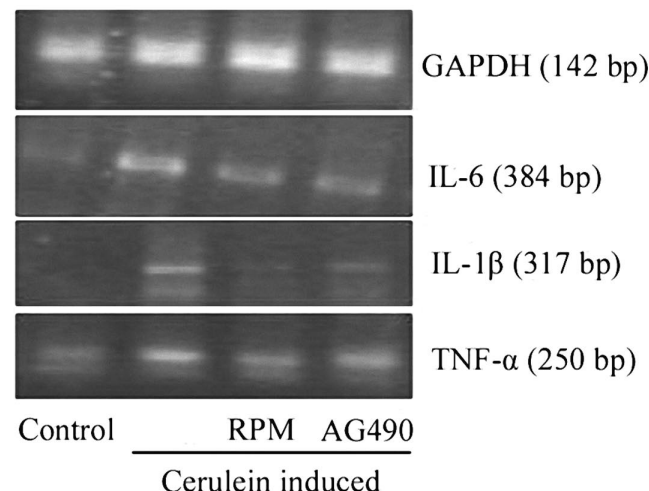

B

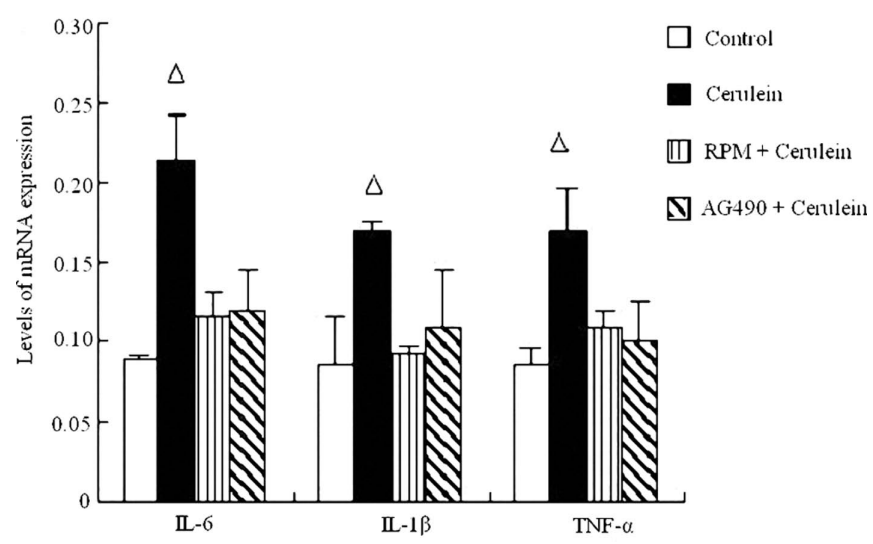

Figure 6. (A) Detection by RT-PCR of the specific mRNA for TNF- $\alpha$, IL-1 $\beta$, IL-6, and GAPDH in each group. Amplification of GAPDH mRNA was used as an internal control. (B) Levels of mRNA for TNF- $\alpha$, IL-1 $\beta$, and IL- 6 in the respective cells were analyzed (measured as the ratio of TNF- $\alpha$, IL-1 $\beta$, or IL-6 band density to that of GAPDH). ${ }^{\triangle} \mathrm{P}<0.05$ vs. cells with all other treatments.

cells). In contrast, the treatment with RPM or AG490 partially counteracted the effects of cerulein on TNF- $\alpha$, IL- $1 \beta$, and IL-6 protein and gene levels $(\mathrm{P}<0.05$, cerulein-stimulated cells).

The effect of RPM or AG490 on the severity of SAP in rats. Histological examination of pancreatic tissues was performed (Fig. 7). There were no remarkable pathological changes in control rats. The broad necrosis of acinar cells and interstitial edema were seen in pancreatic tissues of rats with SAP. The pancreatic morphological changes in RPM or AG490-treated rats was characterized by interstitial edema, but without obvious parenchyma necrosis and hemorrhage. The results of the reflective markers of severity of SAP including pancreatic dry/wet weight ratio, histological score of pancreatic injury, serum TAP and amylase levels are summarized in Table I. These results show that the reflective markers of severity of SAP were significantly decreased in RPM- and AG490-treated rats compared to those of SAP rats, respectively $(\mathrm{P}<0.05)$. In addition, in control rats, the levels of histological score of pancreatic injury and serum amylase were lower than those of RPM- and AG490-treated rats, respectively $(\mathrm{P}<0.05)$.

\section{Discussion}

The excessive systemic inflammatory response in SAP often leads to clinical multiple organ dysfunction syndromes. 
Table I. Histological score of pancreatic injury, pancreatic dry/wet weight ratio, serum amylase and TAP levels in each group.

\begin{tabular}{|c|c|c|c|c|}
\hline Groups & SAP & RPM-treated & AG490-treated & Control \\
\hline Histological score of pancreatic injury & $17.3 \pm 2.1^{\mathrm{a}, \mathrm{b}}$ & $4.9 \pm 1.8^{\mathrm{a}}$ & $5.4 \pm 1.9^{\mathrm{a}}$ & $2.7 \pm 0.67$ \\
\hline Pancreatic dry/wet weight ratio (\%) & $3.13 \pm 0.15^{\mathrm{a}, \mathrm{b}}$ & $2.32 \pm 0.57$ & $2.09 \pm 0.51$ & $1.83 \pm 0.59$ \\
\hline Serum amylase $(\mu / 1)$ & $2656 \pm 397^{\mathrm{a}, \mathrm{b}}$ & $1389 \pm 532^{\mathrm{a}}$ & $1289 \pm 634^{\mathrm{a}}$ & $701 \pm 198$ \\
\hline Serum TAP $(\mu \mathrm{mol} / \mathrm{l})$ & $1.893 \pm 0.175^{\mathrm{a}, \mathrm{b}}$ & $1.478 \pm 0.132^{\mathrm{a}}$ & $1.312 \pm 0.201$ & $1.023 \pm 0.158$ \\
\hline
\end{tabular}

Values are the means $\pm \mathrm{SD}$; ${ }^{\mathrm{a}}<0.01$ vs. the control group; ${ }^{\mathrm{b}} \mathrm{P}<0.01$ vs. the RPM- or AG490-treated groups.

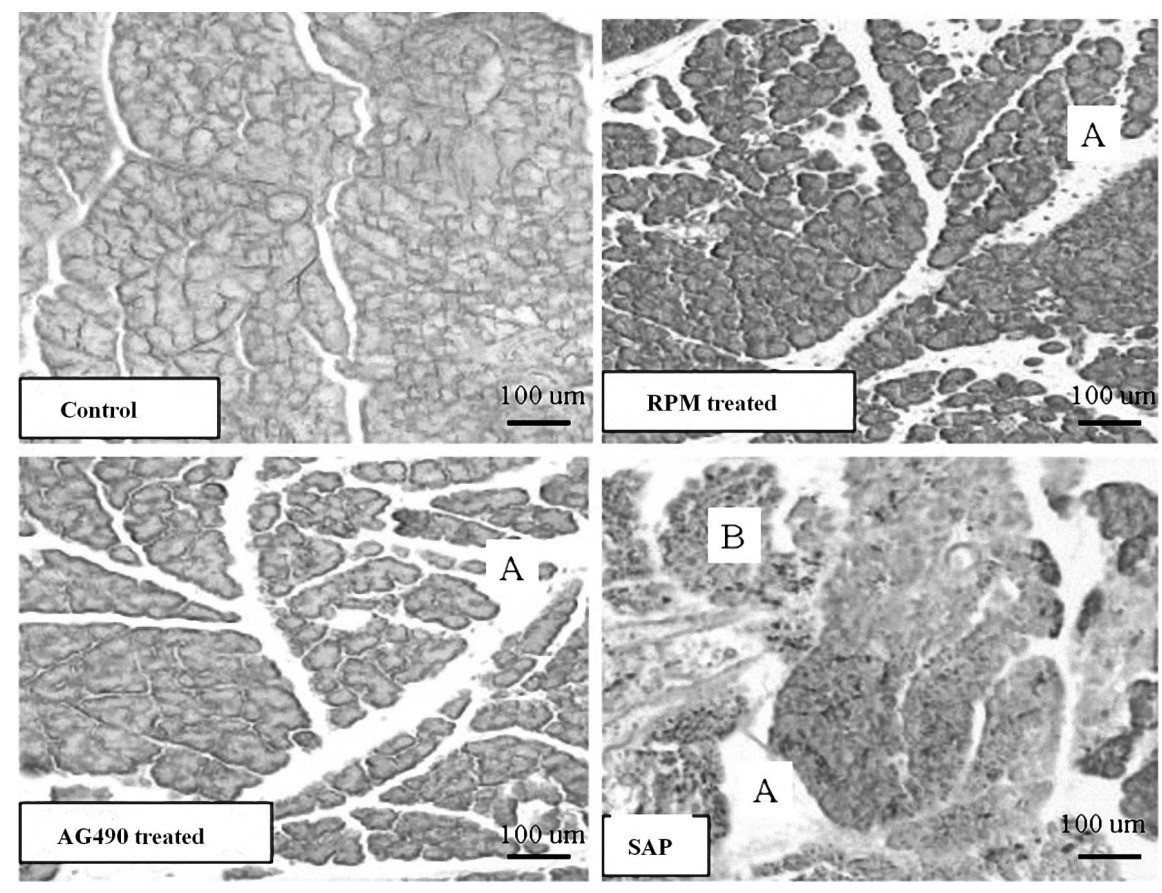

Figure 7. Histological examination of pancreas in each group shown by hematoxylin and eosin staining. There were no remarkable pancreatic injury pathological changes in control rats. The broad necrosis of acinar cells (B) and interstitial edema (A) in rats with severe acute pancreatitis (SAP) are noted. The slight interstitial edema (A) was only observed in RPM- and AG490-treated rats.

Related studies have indicated that the inflammatory mediators such as, IL-6, IL-1 $\beta$ and TNF- $\alpha$, are secreted by macrophages during SAP and augment the inflammatory response that contributes to multi-organ function (9-11). IL-6 is a multifunctional cytokine and is an accurate early predictor of severity for SAP, with a sensitivity range of $89-100 \%(12,13)$. IL-1 $\beta$ is another major cytokine that can drive the excessive systemic inflammatory response. It has been used as a biomarker of disease severity and has similar accuracy to IL-6 in predicting SAP upon admission (14). TNF- $\alpha$ is a key regulator of other pro-inflammatory cytokines and of leukocyte adhesion molecules, and it is a priming activator of immune cells. In recent years, several research lines - mostly derived from animal models and in vitro studies have suggested that TNF- $\alpha$ plays a pivotal role in the pathogenesis of SAP. In particular, it contributes to the systemic progression of the inflammatory response and to the end-organ dysfunction often observed in severe disease (15).

These studies have shown that the JAK/STAT signaling pathway plays an important role in the inflammatory response. The inhibition of JAK-1 might lead to a dramati- cally increased susceptibility to viral and bacterial pathogens (16). Matsukawa (17) has reported that STAT-1 gene knockout mice are moderately resistant to endotoxin shock. Yu et al (18) have suggested that cerulein induces the activity of JAK-2 and STAT-3, which is inhibited by treatment of AR42J cells with AG490. Therefore, it is suggested that the JAK-2/STAT-3 signaling pathway may be the underlying mechanism in the pathogenesis of SAP. Another study has provided evidence that the maximal lung injury after cerulein-induced SAP occurrs in STAT4 or STAT6-deficient mice (19). In pancreatic acinar cells stimulated with TNF- $\alpha$, the activity of JAK-2 and STAT-1 or STAT-3 have been shown to have an impact on the development of pancreatic injury (20). In the present study, the activity of the JAK/STAT signaling pathway was also confirmed to be increased in cerulein-stimulated AR42J cells, especially in terms of the activities of JAK-1, STAT-1 and STAT-3. In addition, the inflammatory cytokines such as TNF- $\alpha$, IL-1 $\beta$, and IL-6, were increased. It is possible that the inflammatory response in pancreatic injury physically and functionally is associated with the JAK-1/STAT-1, STAT-3 activities. The findings thus indicate that the therapeutic 
strategy for SAP should include the modulation of the JAK-1/ STAT-1, STAT-3 signaling pathway.

RPM is a streptomyces derivative that inhibits the mammalian target of the mTOR signaling pathway that is critical for the regulation of cell growth, cell proliferation, cell motility, cell survival $(21,22)$. RPM is widely used as an immunosuppressant in organ transplant recipients and has shown limited toxicities even in immunological disorders (23). In addition, other data directly support the idea that RPM inhibits the activity of STAT-1 (24).

AG490 is a recently developed JAK-2 inhibitor and is part of the synthetically-derived tyrphostin family of tyrosine kinase inhibitors. AG490 inhibits cytokine-induced activation of JAK-2 in eosinophils stimulated with granulocyte-macrophage colony stimulating factor and selectively blocks leukemic cell growth by inducing programmed cell death (25). Related studies have suggested that AG490 also inhibits the IL-2 signaling pathway in the $\mathrm{T}$ cell line, D10, which fails to activate JAK-1, JAK-2, or Tyk2 $(26,27)$. Furthermore, AG490 is an inhibitor of the JAK-2, JAK-3/STAT, JAK-3/acute protein-1 and the JAK-3/mitogen-activated protein kinase signaling pathways and potently inhibits cytokine-independent cell growth in vitro. In the present study, treatment with AG490 inhibited the activity of JAK-1 and STAT-1 proteins and treatment with RPM inhibited the activity of the STAT-1 protein in cerulein-stimulated AR42J cells.

Treatment with AG490 and RPM inhibits not only the JAK-1/STAT-1 pathway, but also may be involved in other signaling pathways. The close correlation between the NF-B expression and the extent of inflammation was reported in SAP by related studies, the results of which suggest that NF-B could be a major inflammatory regulating factor in SAP (28). However, little is known about the relationship between the role of NF-B and of the JAK-1/STAT-1 signaling pathway in the regulation of the systemic inflammatory response during SAP. Based on these findings, we further investigated the effects of RPM and AG490 on the inflammatory response in an in vitro model of SAP to better define a potential role for the inhibitors of JAK-1/STAT-1 signaling pathway for the therapy of SAP. These results demonstrate that RPM and AG490 completely reversed the cerulein-stimulated NF-B activity. This was directly confirmed by measuring the expressions of IK $\beta$, NF-B P65 and of NF-B P50 protein using Western blot analysis. The observed decreases in the expressions of TNF- $\alpha$, IL- $1 \beta$, and IL- 6 at the gene and protein levels indicate that the anti-inflammatory effects of RPM and AG490 are mainly mediated through the crosstalk between the JAK-1/STAT-1 and the NF-B signaling pathways.

Another question that may arise is whether the inhibition of the JAK/STAT signaling pathway by RPM and AG490 attenuates the severity of SAP in vivo. TAP is a small peptide, which is cleaved from the amino-terminal end of trypsinogen during activation. Previous studies have shown that the quantification of TAP in the early phase of SAP provides an accurate prediction of the severity of disease (29). Similarly, serum amylase levels, the histological score of pancreatic injury and the pancreatic dry/wet weight ratio could reflect the severity of pancreatic damage and are increased in SAP. In this study, our data indicate a significant reduction of the examined markers of severity of SAP in rats treated with RPM or AG490 compared to rats with SAP. Therefore, the present study indicates that the inhibitor of JAK-1/STAT-1 activity could attenuate the severity of SAP.

In conclusion, the results provide evidence that cerulein rapidly triggers the activity of the JAK-1/STAT-1, 3 signaling pathway to mediate several inflammatory events including the activity of NF-B and the transcription of the inflammatory mediators. It also documents a novel effect of the inhibitors of the JAK/STAT signaling pathway in vitro, which results in suppression of the NF-B activity and a decrease of the production of inflammatory mediators, events which might be a benefit for pancreatic injury in vivo. The results of this study further suggest that the JAK-1/STAT-1 signaling pathway might become a new target for the regulation of the inflammatory response in SAP.

\section{References}

1. Bhatia M, Wong FL, Cao Y, Lau HY, Huang J, Puneet P and Chevali L: Pathophysiology of acute pancreatitis. Pancreatology 5: 132-144, 2005 .

2. Andersson R, Andersson B, Andersson E, Axelsson J, Eckerwall G, and Tingstedt B: Acute pancreatitis - from cellular signaling to complicated clinical course. HPB (Oxford) 9: 414-420, 2007.

3. O'Shea JJ: Targeting the JAK/STAT pathway for immunosuppression. Ann Rheum Dis 63: 67-71, 2004.

4. O'Shea JJ, Gadina M and Schreiber RD: Cytokine signaling in 2002: new surprises in the Jak/Stat pathway. Cell 109 (Suppl): 121-131, 2002.

5. Gukovskaya AS, Vaquero E, Zaninovic V, Gorelick FS, Lusis AJ, Brennan ML, Holland S and Pandol SJ: Neutrophils and NADPH oxidase mediate intrapancreatic trypsin activation in murine experimental acute pancreatitis. Gastroenterology 122: 974-984, 2002.

6. Dietrich JB: AR4-2J cells: a model to study polypeptide hormone receptors. Biosci Rep 16: 273-288, 1996.

7. Satoh A, Gukovskaya AS, Edderkaoui M, Daghighian MS Reeve JR Jr, Shimosegawa T and Pandol SJ: Tumor necrosis factor-alpha mediates pancreatitis responses in acinar cells via protein kinase $\mathrm{C}$ and proline-rich tyrosine kinase 2 . Gastroenterology 129: 639-651, 2005.

8. Grewal HP, Mohey el Din A, Koth M and Gaber AO: Amelioration of the physiologic and biochemical changes of acute pancreatitis using an anti-TNF-alpha polyclonal antibody. Am J Surg 167: 214-218, 1994.

9. de-Madaria E, Martínez J, Sempere L, Lozano B, SánchezPayá J, Uceda F and Pérez-Mateo M: Cytokine genotypes in acute pancreatitis: association with etiology, severity, and cytokine levels in blood. Pancreas 37: 295-301, 2008.

10. Stimac D, Fisić E, Milić S, Bilić-Zulle L and Perić R: Prognostic values of IL-6, IL-8, and IL-10 in acute pancreatitis. J Clin Gastroenterol 40: 209-212, 2006.

11. Mayer J, Rau B, Gansauge F and Beger HG: Inflammatory mediators in human acute pancreatitis: clinical and pathophysiological implications. Gut 47: 546-552, 2000.

12. Sathyanarayan G, Garg PK, Prasad H and Tandon RK: Elevated level of interleukin- 6 predicts organ failure and severe disease in patients with acute pancreatitis. J Gastroenterol Hepatol 22: 550-554, 2007.

13. Cuzzocrea S, Mazzon E, Dugo L, Centorrino T, Ciccolo A McDonald MC, de Sarro A, Caputi AP and Thiemermann C: Absence of endogenous interleukin- 6 enhances the inflammatory response during acute pancreatitis stimulated by cerulein in mice. Cytokine 18: 274-285, 2002

14. Paszkowski AS, Rau B, Mayer JM, Möller P and Beger HG: Therapeutic application of Caspase 1/interleukin-1betaconverting enzyme inhibitor decreases the death rate in severe acute experimental pancreatitis. Ann Surg 235: 68-76, 2002.

15. Malleo G, Mazzon E, Siriwardena AK and Cuzzocrea S: TNF-alpha as a therapeutic target in acute pancreatitis - lessons from experimental models. Scient World J 7: 431-448, 2007. 
16. Kamezaki K, Shimoda K, Numata A, Matsuda T, Nakayama K and Harada M: The role of Tyk2, STAT- 1 and Stat 4 in LPS-stimulated endotoxin signals. Int Immunol 16: 1173-1179, 2004.

17. Matsukawa A: STAT proteins in innate immunity during sepsis: lessons from gene knockout mice. Acta Med Okayama 61: 239-245, 2007

18. Yu JH, Kim KH and Kim H: Suppression of IL-1beta expression by the Jak 2 inhibitor AG490 in cerulein-stimulated pancreatic acinar cells. Biochem Pharmacol 72: 1555-1562, 2006.

19. Simovic MO, Ballard BR, Gray KD, Gray KD and Stain SC: The STAT4 and STAT6 pathways in pancreatitis-associated lung injury. J Surg Res 137: 10-15, 2007.

20. Robinson K, Vona-Davis L and Riggs D: Peptide YY attenuates STAT1 and STAT3 activation induced by TNF-alpha in acinar cell line AR42J. J Am Coll Surg 202: 788-796, 2006.

21. Weichhart T, Costantino G, Poglitsch M, Rosner M Zeyda M, Stuhlmeier KM, Kolbe T, Stulnig TM, Hörl WH, Hengstschläger M, Müller M and Säemann MD: The TSC-mTOR signaling pathway regulates the innate inflammatory response. Immunity 29: 565-577, 2008.

22. Jia W, Sun V, Tran N, Choi B, Liu SW, Mihm MC Jr, Phung TL and Nelson JS: Long-term blood vessel removal with combined laser and topical rapamycin antiangiogenic therapy: Implications for effective port wine stain treatment. Lasers Surg Med 42: $105-112,2010$.
23. Wu K, Xiang F, Yuan J, Zeng Z, Zhou H, Chang S and Chen ZK A combination of donor specific transfusion and rapamycin prolongs cardiac allograft survival in mice. Transplant Proc 40: 3699-3701, 2008

24. Nepomuceno RR, Balatoni CE, Natkunam Y, Snow AL, Krams SM and Martinez OM: Rapamycin inhibits the interleukin 10 signal transduction pathway and the growth of Epstein Barr virus B-cell lymphomas. Cancer Res 63: 4472-4480, 2003.

25. Meydan N, Grunberger T, Dadi H, Shahar M, Arpaia E, Lapidot Z, Leeder JS, Freedman M, Cohen A, Gazit A, Levitzki A and Roifman CM: Inhibition of acute lymphoblastic leukemia by a Jak2 inhibitor. Nature 379: 645-648, 1996.

26. Wang LH, Kirken RA, Erwin RA, Yu CR and Farrar WL: JAK3, STAT, and MAPK signaling pathways as novel molecular targets for the tyrphostin AG-490 regulation of IL-2-mediated T cell response. J Immunol 162: 3897-3904, 1999.

27. Yamauchi K, Osuka K, Takayasu M, Usuda N, Nakazawa A, Nakahara N, Yoshida M, Aoshima C, Hara M and Yoshida J: Activation of JAK/STAT signaling in neurons following spinal cord injury in mice. J Neurochem 96: 1060-1070, 2006.

28. Algül H, Tando Y, Schneider G, Weidenbach H, Adler G and Schmid RM: Acute experimental pancreatitis and NF-kappaB/ Rel activation. Pancreatology 2: 503-509, 2002.

29. Frossard JL: Trypsin activation peptide (TAP) in acute pancreatitis: from pathophysiology to clinical usefulness. J Pancreas (Online) 2: 69-77, 2001 